CLINICAL STUDY

\title{
Circulating adiponectin levels and cardiovascular risk factors in acromegalic patients
}

\author{
C L Ronchi, S Corbetta, V Cappiello, P S Morpurgo, C Giavoli, P Beck-Peccoz, M Arosio ${ }^{1}$ and A Spada \\ Institute of Endocrine Sciences, University of Milan, Ospedale Maggiore IRCCS, Milan, Italy and ${ }^{1}$ Ospedale S. Giuseppe-Fatebenefratelli A.fa.R., \\ Milan, Italy
}

(Correspondence should be addressed to A Spada, Institute of Endocrine Sciences, Padiglione Granelli, Ospedale Maggiore IRCCS, Via F. Sforza, 3520122 Milan, Italy; Email: anna.spada@unimi.it)

\begin{abstract}
Objective: Adiponectin $(\mathrm{ApN})$ is an adipocytokine expressed in human adipose cells with anti-atherogenic and anti-inflammatory properties that plays a role in the pathophysiology of insulin resistance, metabolic syndrome and coronary artery disease. The aim of the study was to evaluate ApN secretion in patients with acromegaly, a chronic disease associated with insulin resistance and increased cardiovascular mortality, and to correlate $\mathrm{ApN}$ levels with hormonal, metabolic and cardiovascular parameters.

Design and methods: The study included 32 patients with active acromegaly (11 male and 21 female, aged $48 \pm 11$ years, duration of disease: $8 \pm 6$ years, GH: $9.2 \pm 9.8 \mu \mathrm{g} / \mathrm{l}$, IGF-I: $80 \pm 33 \mathrm{nmol} / \mathrm{l}$ (means \pm S.D.)) and 38 control subjects sex- and body mass index (BMI)-matched. In all subjects, serum ApN, leptin and ghrelin levels, BMI, waist circumference, insulin resistance (assessed by homeostasis model assessment and the quantitative insulin check index), lipid profile and blood pressure values were evaluated.

Results: Acromegalic patients and control subjects had similar ApN levels $(9.4 \pm 3.5$ vs $9.5 \pm 4.0 \mathrm{mg} / \mathrm{l}$, NS), while when considering obese subjects acromegalic patients had ApN levels significantly higher than controls $(10.2 \pm 4$ vs $7.5 \pm 3 \mathrm{mg} / \mathrm{l}, \mathrm{P}<0.05)$. No significant correlation between ApN and GH/IGF-I levels or duration of disease was found. ApN concentrations negatively correlated with BMI, waist circumference, glucose and diastolic blood pressure and positively with high-density lipoprotein cholesterol and ghrelin in controls, while all these correlations were lost in acromegalic patients.

Conclusions: We provide evidence that, although metabolic and cardiovascular abnormalities are present in most acromegalic patients, in these subjects ApN levels are not reduced and, contrary to what is found in BMI-matched controls, do not correlate with cardiovascular risk factors. These data support the view that atherosclerosis is not the main determinant of cardiovascular mortality in acromegaly and suggest a permissive action of GH and/or IGF-I excess on ApN secretion.
\end{abstract}

European Journal of Endocrinology 150 663-669

\section{Introduction}

Adiponectin $(\mathrm{ApN})$ is an adipocytokine highly and specifically expressed in human adipose cells. It belongs to the group of adipose regulatory peptides that also includes tumor necrosis factor- $\alpha$, leptin and resistin. It has been demonstrated that $\mathrm{ApN}$ has anti-atherogenic and anti-inflammatory properties with direct effects on endothelial cells and macrophage-to-foam cell transformation (1-4). Previous studies showed that $\mathrm{ApN}$ negatively correlates with the degree of insulin resistance and is able to enhance insulin sensitivity at liver and muscle levels by inhibiting gluconeogenesis and increasing fatty acid oxidation $(1,5-8)$. Low ApN levels have been found in some insulin-resistant conditions, such as obesity (9), lipodystrophy (10), type 2 diabetes mellitus (11) and metabolic syndrome (12), as well as in dyslipidemia (13), essential hypertension (14) and coronary artery disease (15).

Acromegaly is a chronic disease associated with high cardiovascular morbidity and mortality whose pathogenesis is not fully understood. This disease is characterized by the association of a specific cardiomyopathy (16), mainly represented by concentric hypertrophy of the left ventricle, with many other metabolic and cardiovascular alterations. In particular, abnormalities of glucose metabolism, such as impairment of glucose tolerance and reduced insulin sensitivity, have been reported (17-21). Furthermore, other cardiovascular risk factors, such as altered lipid profile, in particular low high-density lipoprotein (HDL)-cholesterol and high small dense low-density lipoprotein (LDL)-cholesterol levels, and blood hypertension are frequently present in these patients $(22,23)$. 
The aim of the study was to evaluate ApN concentrations in patients with active acromegaly and to correlate these values with hormonal, metabolic and cardiovascular parameters. We provide evidence that in acromegalic patients ApN levels are not reduced and, contrary to what is observed in body mass index (BMI)-matched controls, do not correlate with cardiovascular risk factors.

\section{Patients and methods}

\section{Patients}

Thirty-two patients (11 males and 21 females; aged $48 \pm 11$ years (mean \pm S.D.), range 25-70 years) with active acromegaly as documented by high levels of growth hormone $(\mathrm{GH})(9.2 \pm 9.8 \mu \mathrm{g} / \mathrm{l}$, range $2-39.5)$ non-suppressible after oral glucose load $(75 \mathrm{~g})$ and of insulin-like growth factor I (IGF-I) $(80 \pm 33 \mathrm{nmol} / \mathrm{l}$, range 41-209) were included in this study. Ten patients had newly diagnosed disease, while 22 had previously undergone unsuccessful transphenoidal adenomectomy and nine of them had also undergone radiotherapy. The duration of disease was $8 \pm 6$ years (range 1-25). All patients had been free from medical treatment with somatostatin analogues or dopamine agonists for at least 3 months. BMI ranged from 20.8

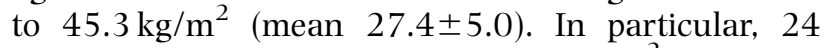
acromegalic patients had BMI $<30 \mathrm{~kg} / \mathrm{m}^{2}$ (normaloverweight) and eight BMI $>30 \mathrm{~kg} / \mathrm{m}^{2}$ (obese). Waist circumference ranged from 76 to $139 \mathrm{~cm}$ (mean $96.2 \pm 16.0 \mathrm{~cm}$ ). Twenty-six patients had insulin resistance as assessed by homeostasis model assessment (HOMA-IR) (mean values: $4.7 \pm 4.0)$ and the quantitative insulin check index (QUICKI) (mean values: $0.32 \pm 0.04)$ formulas, nine impaired glucose tolerance and three diabetes mellitus type 2 (mean glucose levels: $5.6 \pm 2.0 \mathrm{mmol} / \mathrm{l}$ ). As far as other cardiovascular risk factors were concerned, 29 patients had dyslipidemia (mean total cholesterol levels: $216 \pm 39 \mathrm{mg} / \mathrm{dl}$, HDLcholesterol: $43 \pm 9 \mathrm{mg} / \mathrm{dl}$, LDL-cholesterol: $150 \pm 35$ $\mathrm{mg} / \mathrm{dl}$, triglycerides (TGs): $114 \pm 50 \mathrm{mg} / \mathrm{dl}$ ) and 19 blood hypertension (mean systolic blood pressure (SBP): $130 \pm 15$ and diastolic blood pressure (DBP): $87 \pm 11 \mathrm{mmHg}$ ), both evaluated following ATPIII criteria (24). Furthermore, 15 patients presented cardiac abnormalities: seven patients had septal and/or ventricular concentric hypertrophy, five valvulopathy, three cardiac dilatation and three documented coronary artery disease of atherosclerotic origin. In particular, one had developed a previous myocardial infarction and two had abnormal resting and exercise ECG stress testing. Nine patients (seven male and two female, $28 \%$ of total) were affected by central hypogonadism and $22 \%$ by central hypocortisolism and/or hypothyroidism that were adequately substituted.

\section{Control group}

A total of 38 subjects sex- and age-matched (13 male and 25 female, age 39 \pm 14 years, range 23-73) were included in this study as a control group. These subjects were also matched for BMI $\left(26.7 \pm 70 \mathrm{~kg} / \mathrm{m}^{2}\right.$, range $190-44.3)$ and waist circumference $(89.1 \pm 17.7 \mathrm{~cm}$, range $700-1260)$ since these parameters have been previously identified as main determinants of $\mathrm{ApN}$ levels. Twenty-eight controls had BMI $<30 \mathrm{~kg} / \mathrm{m}^{2}$ (normal-overweight) while ten had BMI $>30 \mathrm{~kg} / \mathrm{m}^{2}$ (obese). All these subjects were not taking any medical treatment. The study was approved by the local Ethical Committee and all subjects provided their informed consent before participation.

\section{Study protocol}

Anthropometric parameters (BMI and waist circumference, taken at the level of the umbilicus in the standing position), were measured in all subjects. After an overnight fast, a peripheral venous blood sample was drawn from all subjects for the measurement of circulating ApN, leptin and ghrelin levels. Glucose metabolism (determined by glucose, insulin levels and insulin resistance), lipid profile (by total, HDL- and LDL-cholesterol and TG concentrations), and blood pressure (by SBP and DBP values) were measured in all patients. In acromegalic patients, $\mathrm{GH}$ and insulin-like growth factor (IGF)-I levels were also evaluated.

\section{Assays}

Serum ApN concentrations were measured by ELISA (B-Bridge International, Inc., San Jose, CA, USA), serum leptin levels by IFMA (DRG International, Mountainside, NJ, USA) and ghrelin levels by an RIA kit (Phoenix Pharmaceuticals, Inc., Belmont, CA, USA) that uses a polyclonal antibody recognizing the C-terminal end of ghrelin, i.e. total ghrelin. Serum GH levels were assayed by IFMA (AutoDelfia kit; Wallac OY, Turku, Finland) and serum IGF-I by RIA (Mediagnost, Tübingen, Germany). Serum insulin was measured by ELISA (Medgenix-Ins-EASIA; Biosource Europe, Nivelles, Belgium) and plasma glucose by an autoanalyzer with the hexokinase method (Roche Diagnostics, Mannheim, Germany).

Insulin resistance or sensitivity degree was determined using the HOMA-IR (HOMA-IR = fasting insulin (FI) $(\mathrm{mU} / \mathrm{l}) \times$ fasting glucose $(\mathrm{FG})(\mathrm{mmol} / \mathrm{l}) / 22.5)$ and QUICKI $($ QUICKI $=1 /(\log$ FG $(\mathrm{mg} / \mathrm{dl})+\log \mathrm{FI}(\mathrm{mU} / \mathrm{l})))$ $(25,26)$. Serum total cholesterol, HDL-cholesterol and TGs were determined by an autoanalyzer with a colorimetric enzymatic assay (Roche Diagnostics). LDL-cholesterol levels were evaluated by the formula: $\quad$ LDL-cholesterol $=$ total cholesterol $-\mathrm{HDL}$ cholesterol - (TG/5). 


\section{Statistical analysis}

The results are expressed as means \pm S.D. unless otherwise stated. Data were tested for normality of distribution by the Kolmogorov-Smirnov test and consequently GH, glucose and HOMA-IR were log-transformed to obtain normal distribution. Statistical analysis was carried out using an unpaired two-tailed Student's $t$-test with Welch correction if variances were significantly different. Linear regression analysis was used to determine correlation coefficients between different parameters in each group separately. Values of $P<0.05$ were considered statistically significant.

\section{Results}

\section{ApN levels in acromegalic patients}

Circulating ApN concentrations were similar in acromegalic patients $(9.4 \pm 3.5 \mathrm{mg} / \mathrm{l})$ and control subjects $(9.5 \pm 4.0 \mathrm{mg} / \mathrm{l}, \mathrm{NS})$. The subgroup of obese acromegalic patients showed ApN levels significantly higher than obese controls $(10.2 \pm 4.0$ vs $7.5 \pm 3.0 \mathrm{mg} / \mathrm{l}$, $P<0.05)$. In normal-weight control subjects $\mathrm{ApN}$ was significantly lower in males compared with females $(7.0 \pm 1.0$ vs $11.0 \pm 4.0 \mathrm{mg} / \mathrm{l}, P<0.05)$, while gender differences were absent in obese controls and in acromegalic patients. No significant correlation between ApN and GH/IGF-I levels or the duration of disease was observed in acromegalic patients.

\section{BMI and waist circumference}

In control subjects, circulating ApN levels negatively correlated with BMI $(P<0.05, r=0.36)$ and waist circumferences $(P<0.05, r=-0.41)$. Both these correlations were absent in the acromegalic group (Fig. 1).

\section{Adipose tissue regulatory peptides}

In acromegalic patients, circulating levels of leptin and ghrelin were significantly lower than those detected in control subjects $(9.0 \pm 5.0$ vs $28.5 \pm 30 \mathrm{ng} / \mathrm{ml}$, $P<0.005$, and $167 \pm 101$ vs $316 \pm 143 \mathrm{pmol} / \mathrm{l}$, $P<0.0005$ respectively). Serum leptin levels positively correlated with waist circumference values in healthy controls $(P<0.005$ and $r=0.56)$ while they did not correlate in acromegalic patients. In both groups, no significant correlation between $\mathrm{ApN}$ and leptin was observed (data not shown). Furthermore, ApN levels significantly correlated with ghrelin levels $(P<0.05$, $r=0.47)$ in control subjects, but not in acromegalic patients (Fig. 2).

\section{Insulin resistance and glucose metabolism}

Circulating ApN levels negatively correlated with logglucose levels $(P<0.05, r=-0.35)$ in control subjects, while no significant correlation was detected in acromegalic patients (Fig. 3). No significant correlations were found between ApN and insulin, log-HOMA-IR or QUICKI values in both groups. Furthermore, the three diabetic patients, the nine with impaired glucose tolerance and the 20 euglycemic acromegalic patients had similar ApN concentrations (9.5 $44.9,10.1 \pm 3.5$ and $9.1 \pm 3.5 \mathrm{mg} / \mathrm{l}$ respectively, NS).

\section{CONTROLS}
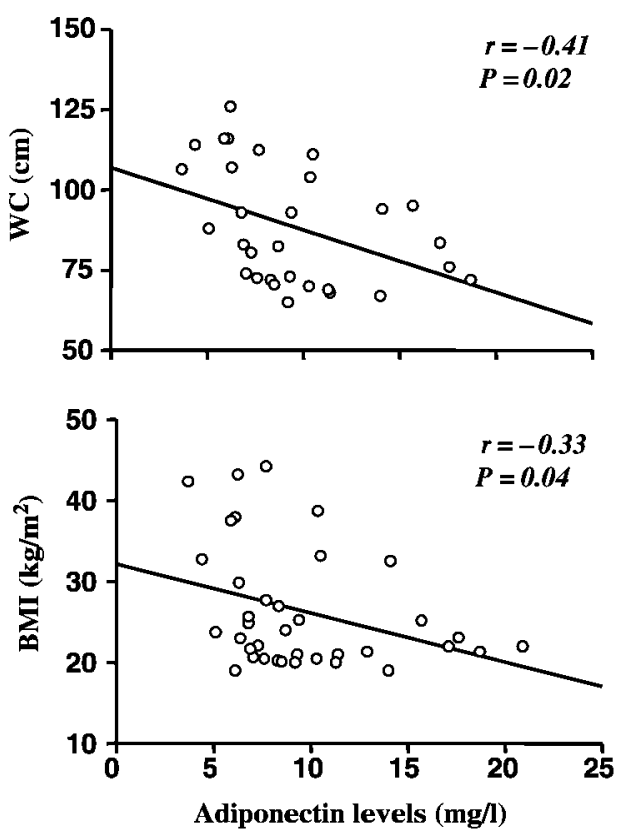

ACROMEGALICS
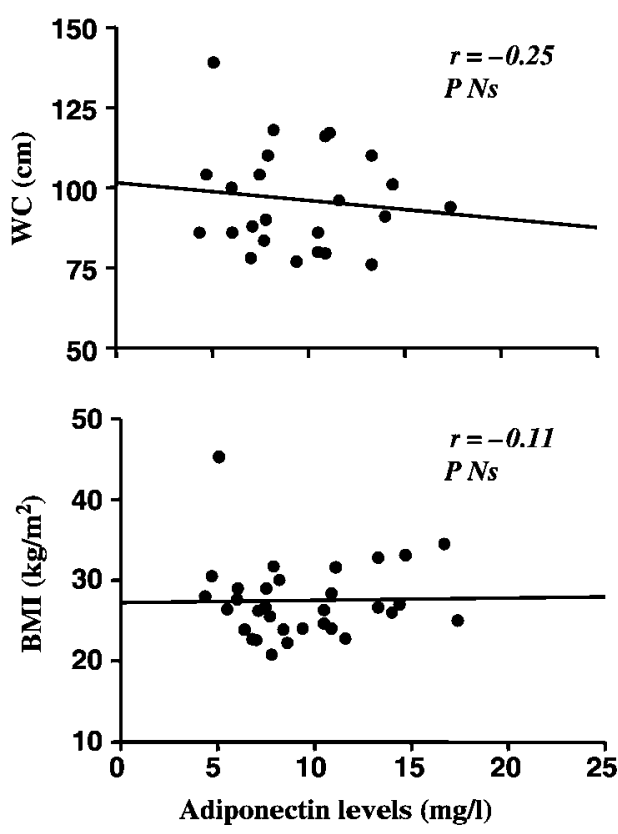

Figure 1 Correlation of serum ApN levels with BMI and waist circumference (WC) in control subjects and acromegalic patients. 


\section{CONTROLS}

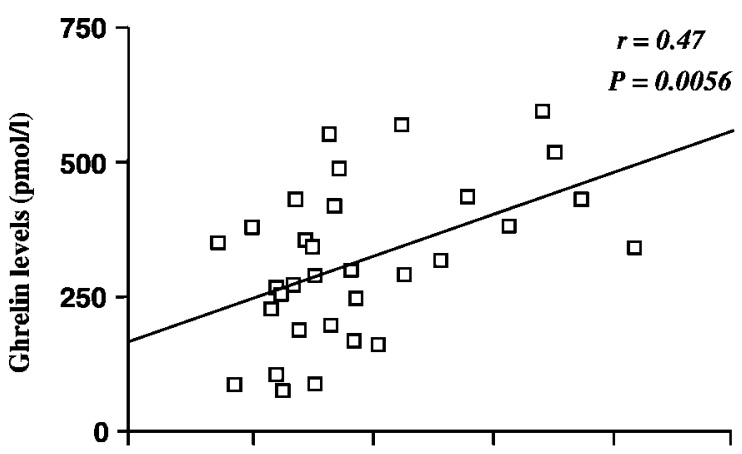

ACROMEgALICS

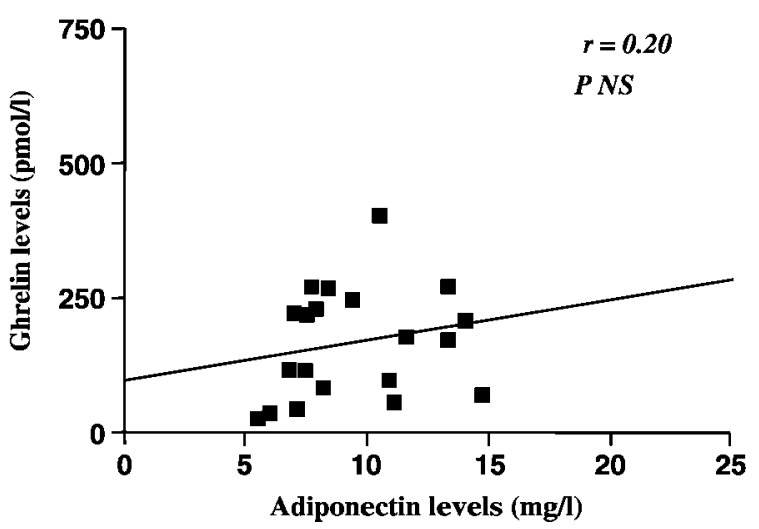

Figure 2 Correlation of serum ApN levels with ghrelin and leptin levels in control subjects and acromegalic patients.

\section{Lipid profiles and blood pressure}

Serum ApN levels positively correlated with HDLcholesterol $(P<0.05, r=0.48)$ (Fig. 3) and showed a negative trend with TGs $(P=0.07)$ in control subjects. In acromegalic patients no correlation between ApN and any one of these lipid profile parameters was found (Fig. 3).

In the control subjects, ApN levels showed a significant negative correlation with DBP $(P<0.05$, $r=-0.41$ ) but not with SBP. No correlation was present in acromegalic patients (Fig. 3).

\section{Discussion}

In this study we demonstrated that ApN levels were not reduced and did not correlate with cardiovascular risk factors in acromegaly. Acromegalic patients present many metabolic alterations, such as insulin resistance, altered lipid metabolism and arterial blood hypertension, that have been reported to be associated with hypoadiponectinemia in both obese and normalweight subjects $(11-14)$. Although on the basis of these observations acromegalic patients would be anticipated to have low ApN levels, the present study failed to find this metabolic alteration. In particular, normal-overweight acromegalic patients showed ApN levels superimposable on those found in BMI-matched healthy subjects, while in obese patients $\mathrm{ApN}$ levels were even higher than those observed in obese controls. This observation is in agreement with previously reported data (27).

Most of the correlations between ApN levels and metabolic parameters observed in healthy controls were lost in acromegalic patients. First, the expected negative correlation between $\mathrm{ApN}$ and BMI was only observed in healthy control subjects. However, since evidence indicates that $\mathrm{ApN}$ levels negatively correlate with body fat mass $(28,29)$, the lack of correlation between $\mathrm{ApN}$ and BMI in acromegalic patients may depend on the fact that these patients had less adipose tissue mass than BMI-matched controls $(30,31)$, as also indicated by the low leptin levels (27). However, in acromegalic patients $\mathrm{ApN}$ levels did not correlate even with waist circumference, which is actually considered one of the most reliable indices for abdominal visceral adipose tissue. Therefore, these data suggest a minor involvement of adipose tissue in determining ApN levels in acromegaly. Admittedly, the percent body fat should be directly assessed in acromegalic patients in order to drawn final conclusions.

Secondly, although most acromegalic patients of this series presented insulin resistance and more than onethird of them had impaired glucose tolerance or diabetes, no correlation between ApN levels and insulin resistance was observed, in agreement with a previous report that also failed to find any correlation between insulin resistance and resistin (27). The same pattern was observed by analyzing other adipose tissue regulatory peptides. In this study, the levels of ghrelin, an acylpeptide gut-brain hormone that negatively correlates with fasting insulin and/or insulin resistance (32, 33), was found to positively correlate with $\mathrm{ApN}$ levels in healthy controls, while this relationship was absent in the acromegalic group. Taken together, these data suggest that the changes in $\mathrm{ApN}$, and possibly resistin, do not contribute to insulin resistance in acromegaly.

Finally, in the present study we considered other cardiovascular risk factors that have been shown to be frequently present in acromegaly and to be associated with hypoadiponectinemia. As expected, acromegalic patients showed several abnormalities in lipid profile parameters and mild blood hypertension. In agreement with previous studies, healthy controls had ApN levels positively correlated with HDL-cholesterol, while the negative correlation with TGs was not significant, probably due to the relatively low number of subjects studied. Moreover, although data on the relationships between $\mathrm{ApN}$ and blood pressures are still controversial, ApN levels were found to negatively correlate with DBP in controls. However, no correlation between these cardiovascular risk factors and $\mathrm{ApN}$ levels was observed in acromegalic patients. 
CONTROLS
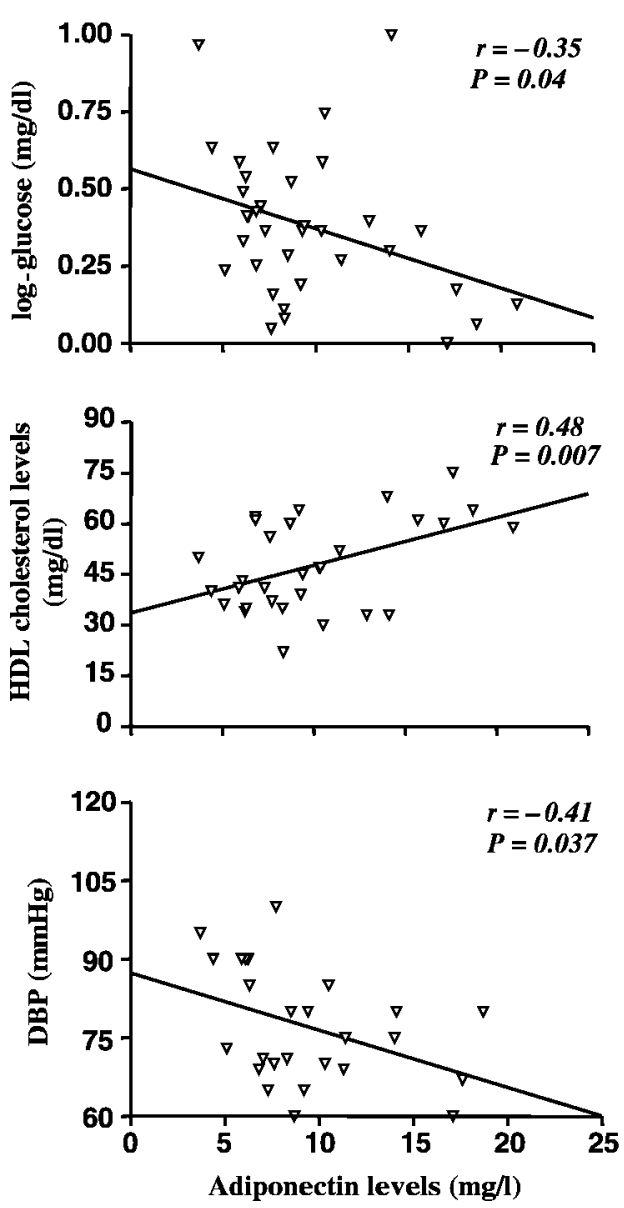

Taken together these data indicate that the metabolic abnormalities observed in acromegalic patients, which included increased body fat, insulin resistance, dyslipidemia and hypertension, were not accompanied by the expected decline in ApN secretion, suggesting a possible role of $\mathrm{GH}$ and IGF-I excess on ApN release from adipose tissue. The in vitro studies so far available showed that GH had any direct positive effect on ApN expression in 3T3-L1 adipocytes (34). Conversely, it has been demonstrated that IGF-I, like insulin, stimulates the expression of $\mathrm{ApN}$ gene in human mature adipocytes (35). Therefore, it is temping to speculate that although we could not find a positive correlation between ApN and IGF-I levels, the presence of normal, instead of decreased, ApN levels in acromegalic patients might be due to the stimulatory action of IGF-I, able to counterbalance insulin resistance. In this respect, acromegaly would differ from the other classic conditions of insulin resistance, such as obesity and type 2 diabetes, that are associated with hypoadiponectinemia $(9,11)$. Although it has been demonstrated that $\mathrm{ApN}$ enhances insulin sensitivity at liver and muscle levels (5-8), the impact of the maintained $\mathrm{ApN}$ secretion on insulin resistance in acromegaly
ACROMEgalics

$r=-0.11$

$P N S$

Figure 3 Correlation between serum ApN levels and log-glucose, HDL-

cholesterol levels, and DBP in control subjects and acromegalic patients.

remains to be established. Similarly, taking into consideration the anti-atherogenic and anti-inflammatory properties of $\mathrm{ApN}$ at the endothelial cell level $(2-4)$, an action of $\mathrm{ApN}$ in counteracting the pathophysiological effects of cardiovascular risk factors may be envisaged. In this respect, it is worth noting that while almost one-half of acromegalic patients of this series presented cardiac anomalies, only three of them had documented coronary artery disease. Moreover, previous studies reported that in acromegalic patients well-defined carotid wall plaques were as frequent as in healthy subjects (36), consistent with the view that atherosclerotic vascular damage does not represent the main determinant of elevated cardiovascular mortality in acromegaly (23).

In conclusion, although most acromegalic patients had abnormalities in glucose metabolism, lipid profile and/or blood pressure, they did not show the expected hypoadiponectinemia, suggesting a possible permissive role of GH and/or IGF-I excess on ApN secretion. The impact of normal or even high ApN levels on the clinical manifestations of the metabolic alterations present in acromegalic patients remains to be investigated. 


\section{Acknowledgements}

The authors are grateful to Mrs Antonia Maffini and Mr Helios Ingrassano for expert technical assistance and to Mrs Rita Deriu for nursing help. The present study was partially supported by research grants from Ministero dell'Università and Ricerca Scientifica (MURST, Rome) and from Ospedale Maggiore IRCCS (Milan).

\section{References}

1 Diez JJ \& Iglesias P. The role of the novel adipocyte-derived hormone adiponectin in human disease. European Journal of Endocrinology 2003148 293-300.

2 Yamauchi T, Kamon J, Waki H, Imai Y, Shimozawa N, Hioki K et al. Globular adiponectin protected ob/ob mice from diabetes and ApoE-deficient mice from atherosclerosis. Journal of Biological Chemistry 2003278 2461-2468.

3 Ouchi N, Kihara S, Arita Y, Nishida M, Matsuyama A, Okamoto Y et al. Adipocyte-derived plasma protein, adiponectin, suppresses lipid accumulation and class A scavenger receptor expression in human monocyte-derived macrophages. Circulation 2001103 1057-1063.

4 Fernandez-Real JM, Lopez-Bermejo A, Casamitjana R \& Ricart W. Novel interactions of adiponectin with the endocrine system and inflammatory parameters. Journal of Clinical Endocrinology and Metabolism $2003 \mathbf{8 8} 2714-2718$.

5 Weyer C, Funahashi T, Tanaka S, Hotta K, Matsuzawa Y, Pratley RE et al. Hypoadiponectinemia in obesity and type 2 diabetes: close association with insulin resistance and hyperinsulinemia. Journal of Clinical Endocrinology and Metabolism 200186 1930-1935.

6 Silha JV, Krsek M, Skrha JV, Sucharda P, Nyomba BL \& Murphy LJ. Plasma resistin, adiponectin and leptin levels in lean and obese subjects: correlations with insulin resistance. European Journal of Endocrinology $2003149331-335$.

7 Yamauchi T, Kamon J, Waki H, Terauchi Y, Kubota N, Hara K et al. The fat-derived hormone adiponectin reverses insulin resistance associated with both lipoatrophy and obesity. Nature Medicine $20017941-946$.

8 Fruebis J, Tsao TS, Javorschi S, Ebbets-Reed D, Erickson MR, Yen FT et al. Proteolytic cleavage product of 30-kDa adipocyte complement-related protein increases fatty acid oxidation in muscle and causes weight loss in mice. PNAS 200198 2005-2010.

9 Arita Y, Kihara S, Ouchi N, Takahashi M, Maeda K, Miyagawa J et al. Paradoxical decrease of an adipose-specific protein, adiponectin, in obesity. Biochemical and Biophysical Research Communications 1999257 79-83.

10 Haque WA, Shimomura I, Matsuzawa Y \& Garg A. Serum adiponectin and leptin levels in patients with lipodystrophies. Journal of Clinical Endocrinology and Metabolism $2002 \quad \mathbf{8 7}$ 2395-2398.

11 Hotta K, Funahashi T, Arita Y, Takahashi M, Matsuda M, Okamoto Y et al. Plasma concentrations of a novel, adiposespecific protein, adiponectin, in type 2 diabetic patients. Arteriosclerosis, Thrombosis and Vascular Biology $2000 \quad 20$ 1595-1599.

12 Kishida K, Nagaretani H, Kondo H, Kobayashi H, Tanaka S, Maeda $\mathrm{N}$ et al. Disturbed secretion of mutant adiponectin associated with the metabolic syndrome. Biochemical and Biophysical Research Communications 2003306 286-292.

13 Matsubara M, Maruoka S \& Katayose S. Decreased plasma adiponectin concentrations in women with dyslipidemia. Journal of Clinical Endocrinology and Metabolism 200287 2764-2769.
14 Adamczak M, Wiecek A, Funahashi T, Chudek J, Kokot F \& Matsuzawa Y. Decreased plasma adiponectin concentration in patients with essential hypertension. American Journal of Hypertension $20031672-75$.

15 Kumada M, Kihara S, Sumitsuji S, Kawamoto T, Matsumoto S, Ouchi N et al. Osaka CAD Study Group. Coronary artery disease. Association of hypoadiponectinemia with coronary artery disease in men. Arteriosclerosis, Thrombosis and Vascular Biology 200323 $85-89$.

16 Damjanovic SS, Neskovic AN, Petakov MS, Popovic V, Vujisic B, Petrovic $\mathrm{M}$ et al. High output heart failure in patients with newly diagnosed acromegaly. American Journal of Medicine 2002 $112610-616$.

17 Melmed S. Acromegaly. New England Journal of Medicine 1990 322 966-977.

18 Hansen I, Tsalikian E, Beaufrere B, Gerich J, Haymond M \& Rizza R. Insulin resistance in acromegaly: defects in both hepatic and extrahepatic insulin action. American Journal of Physiology 1986 250 E269-E273.

19 Moller N, Schmitz O, Joorgensen JO, Astrup J, Bak JF, Christensen SE et al. Basal and insulin-stimulated substrate metabolism in patients with active acromegaly before and after adenomectomy. Journal of Clinical Endocrinology and Metabolism $1992 \quad \mathbf{7 4}$ $1012-1019$.

20 Kasayama S, Otsuki M, Takagi M, Saito H, Sumitani S, Kouhara H et al. Impaired beta-cell function in the presence of reduced insulin sensitivity determines glucose tolerance status in acromegalic patients. Clinical Endocrinology $2000 \mathbf{5 2} 549$-555.

21 Ronchi CL, Orsi E, Giavoli C, Cappiello V, Epaminonda P, BeckPeccoz $\mathrm{P}$ et al. Evaluation of insulin resistance in acromegalic patients before and after treatment with somatostatin analogues. Journal of Endocrinological Investigation 2003 26 533-538.

22 Arosio M, Sartore G, Rossi CM, Casati G, Faglia G \& Manzato E. LDL physical properties, lipoprotein and Lp(a) levels in acromegalic patients. Effects of octreotide therapy. Italian Multicenter Octreotide Study Group. Atherosclerosis $2000151551-557$.

23 Clayton RN. Cardiovascular function in acromegaly. Endocrine Reviews $200324272-277$.

24 Expert Panel on Detection, Evaluation, and Treatment of High Blood Cholesterol in Adults. Executive summary of the third report of the National Cholesterol Education Program (NCEP), Expert Panel on Detection, Evaluation, and Treatment of High Blood Cholesterol in Adults (ATPIII). Journal of the American Medical Association 2001287 356-359.

25 Matthews DR, Hosker JP, Rudenski AS, Naylor BA, Treacher DF \& Turner RC. Homeostasis model assessment: insulin resistance and beta-cell function from fasting plasma glucose and insulin concentrations in man. Diabetologia $1985 \mathbf{2 8} 412-419$.

26 Katz A, Nambi SS, Mather K, Baron AD, Follmann DA, Sullivan G et al. Quantitative insulin sensitivity check index: a simple, accurate method for assessing insulin sensitivity in humans. Journal of Clinical Endocrinology and Metabolism $2000852402-2410$.

27 Silha JV, Krsek M, Hana V, Marek J, Jezkova J, Weiss V et al. Perturbations in adiponectin, leptin and resistin levels in acromegaly: lack of correlation with insulin resistance. Clinical Endocrinology $200358736-742$.

28 Stefan N, Vozarova B, Funahashi T, Matsuzawa Y, Ravussin E, Weyer C et al. Plasma adiponectin levels are not associated with fat oxidation in humans. Obesity Research 200210 1016-1020.

29 Cnop M, Havel PJ, Utzschneider KM, Carr DB, Sinha MK, Boyko EJ et al. Relationship of adiponectin to body fat distribution, insulin sensitivity and plasma lipoproteins: evidence for independent roles of age and sex. Diabetologia $2003 \mathbf{4 6} 459-469$.

30 Brummer RJM, Lonn L, Kvist H, Grangard U, Bengtsson BA \& Sjostrom L. Adipose tissue and muscle volume determination by computed tomography in acromegaly, before and 1 year after adenomectomy. European Journal of Clinical Investigation 199323 199-205. 
31 Miyakawa M, Tsushima T, Murakami H, Isozaki O, Demura H \& Tanaka T. Effect of growth hormone $(\mathrm{GH})$ on serum concentrations of leptin: study in patients with acromegaly and GH deficiency. Journal of Clinical Endocrinology and Metabolism 1998 833476 -3479.

32 Cappiello V, Ronchi C, Morpurgo PS, Epaminonda P, Arosio M, Beck-Peccoz $\mathrm{P}$ et al. Circulating ghrelin levels in basal conditions and during glucose tolerance test in acromegalic patients. European Journal of Endocrinology 2002 147 189-194.

33 Pagotto U, Gambineri A, Vicennati V, Heiman ML, Tschop M \& Pasquali R. Plasma ghrelin, obesity and the polycystic ovary syndrome: correlation with insulin resistance and androgen levels. Journal of Clinical Endocrinology and Metabolism 200287 5625-5629.

34 Fasshauer M, Klein J, Neumann S, Eszlinger M \& Paschke R. Hormonal regulation of adiponectin gene expression in 3T3-L1 adipocytes. Biochemical and Biophysical Research Communications 2002290 1084-1089.

35 Halleux CM, Takahashi M, Delporte ML, Detry R, Funahashi T, Matsuzawa $\mathrm{Y}$ et al. Secretion of adiponectin and regulation of apM1 gene expression in human visceral adipose tissue. Biochemical and Biophysical Research Communications $2001 \mathbf{2 8 8}$ $1102-1107$

36 Colao A, Spiezia S, Cerbone G, Pivonello R, Marzullo P, Ferone D et al. Increased arterial intima-media thickness by B-M mode echodoppler ultrasonography in acromegaly. Clinical Endocrinology $2001 \mathbf{5 4} 515-524$.

Received 24 October 2003

Accepted 26 January 2004 